\title{
Ambiente de Ensino de Química Orgânica Baseado em Gamificação
}

\author{
Anita Maria da Rocha Fernandes, Fernando Santos Castro \\ Universidade do Vale de Itajaí, Curso de Ciência da Computação - Campus São José - \\ São José - SC - Brasil \\ anita.fernandes@univali.br; fernandocastro1988@gmail.com
}

\begin{abstract}
Gamification makes use of the elements present in games, such as rewards, feedback, rankings and exchanges and their application in teaching can make students be motivated to perform certain tasks or competitions to achieve the course objectives. Tasks can encourage and promote greater interaction among students, allowing for a harmonious development of the class as a whole, with targets being met collectively and not only through individual notes. This can assist in teaching abstract concepts related with organic chemistry. In this context, this paper presents an environment for teaching organic chemistry based on gamification, and instructional content available on a web environment.
\end{abstract}

Resumo. Gamificação faz uso dos elementos presentes nos Games, como por exemplo, recompensa, feedback, rankings e trocas e sua aplicação no ensino pode fazer com que os alunos sejam motivados a cumprir determinadas tarefas ou gincanas para atingir os objetivos do curso. As tarefas podem incentivar e promover maior interação entre os alunos, possibilitando um desenvolvimento harmonioso da turma como um todo, com metas sendo atingidas de maneira coletiva e não somente através de notas individuais. Isto pode auxiliar no ensino de conceitos abstratos com os relacionados a Química Orgânica. Neste contexto, este artigo apresenta um ambiente de ensino de química orgânica "gamificado", tendo o conteúdo instrucional disponibilizado na web.

\section{Introdução}

Nos últimos anos, pesquisadores interessados no ensino de Química, vêm discutindo sobre como tornar as disciplinas relacionadas à Química, mais atraentes. É fato, por exemplo, que a natureza extremamente abstrata do conteúdo, gera, na maioria das vezes o desinteresse e a falta de estímulo, em cursos que não tem a Química como um fim, como por exemplo, Medicina, Nutrição, Odontologia [AZEVEDO 2005]. Tais pesquisas têm focado em novas formas de ensino, baseadas no avanço da tecnologia da informação, ambientes virtuais de Ensino/Aprendizagem, redes sociais e games [CRISP et al, 2011]; [ANTONOGLOU, CHARISTOS \& SIGALAS 2011]; [STIZICKLAND KRAFT \& BHATTACHARYYA 2010]; [EILKS \& BYERS 2010]; [GREGORIUS et al 2010], buscando se aproximar da maneira como as gerações atuais trabalham seu processo de aprendizagem.

As disciplinas de Química requerem uma atenção e um comprometimento por parte dos alunos, devido a complexidade e abstração de seus conceitos [CRISP et al 2011]. O processo de Ensino/Aprendizagem de Química requer uma capacidade criativa do aluno para, por exemplo, imaginar como é a estrutura de um átomo. Esta necessidade 
não se restringe ao ensino médio, e os mesmos problemas são detectados no ensino superior [ANTONOGLOU, CHARISTOS \& SIGALAS 2011]. É necessário criar mecanismos ou utilizar tecnologias que auxiliem o aluno no desenvolvimento da capacidade de construção representativa de circunstâncias ou modelo, em questões que necessitam de compreensão de conceitos abstratos [CRISP et al 2011].

Dentro deste cenário, Jenkins et al (2006), com o projeto New Media Literacies (NML), desenvolvido no MIT, pesquisam as habilidades e competências necessárias para que os jovens possam participar adequedamente do mundo de hoje. Com a cultura da participação, o envolvimento na comunidade tornou-se mais importante do que a expressão individual. Quase todas as novas habilidades envolvem colaboração. A lista de habilidades proposta pelo NML [JENKINS et al 2006] inclui: espírito de jogador; performance; simulação: habilidade de interpretar e construir modelos dinâmicos de processos do mundo real; apropriação; multitarefa; cognição distribuída; inteligência coletiva; senso crítico; navegação transmídia; networking; negociação; e visualização.

A maioria destas habilidades, segundo Mattar (2010), tem sido muito pouco ensinada nas escolas e muito mais praticada pelos jovens nos momentos de lazer, em games e mundos virtuais. Ainda segundo Mattar (2010), o modo de funcionamento dos games é semelhante ao modo como as novas gerações aprendem. Games geram envolvimento como nenhuma outra mídia, o que se deve a vários fatores: diversão, jogo, regras e estrutura, objetivos, interatividade, resultados e feedback, fluxo, dentre outros. Para Prensky (2007), os princípios do aprendizado baseado em games seriam: é divertido, as pessoas se consideram jogadores, mais do que aprendizes, é viciante, as habilidades do jogador progridem conforme ele joga, e o jogo encoraja reflexão sobre o que esta sendo aprendido.

Sontag (2009), com a sua teoria "Social and Cognitive-Connectedness Schemata" (SCCS), que integra teorias da aprendizagem com mecânicas de games, apresenta que os elementos apresentados nas mecânicas de games têm a função de fomentar a atenção, memória e motivação dos alunos, facilitando tanto schematas de conexões socias quanto cognitivas. Na definição de Sontag (2009), schematas são as estruturas existentes de conhecimento e compreensão sobre as quais novos conhecimentos são construídos; como tais, elas são moldadas pelas experiências anteriores dos alunos e moldam todo o aprendizado futuro. Elementos de games estimulam a lembrança do aprendizado anterior, geram desempenho e fornecem feedback, assim como oferecem oportunidades para os alunos interagirem. Além disto, os elementos de games tocam no domínio afetivo, uma fonte de motivação potente, mas muitas vezes subutilizada [MATTAR 2010]. A aplicação de mecânicas de games em aplicativos e/ou ambientes cujo objetivo principal não é o entretenimento, tendo como finalidade engajar o usuário, recebe o nome de Gamificação [COHEN 2011]. Segundo Cohen (2011), Gamification é o processo de utilizar mecânicas e conceitos de Games para envolver o público e resolver problemas. Não quer dizer necessariamente a obrigatoriedade de desenvolver um game, mas aplicar as características que tornam os jogos envolventes em produtos e serviços.

Segundo Aldrich (2009), existem três necessidades básicas que devem ser pensadas para criar um produto ou serviço dentro da lógica de Gamification: Rewards (recompensas): que servem de feedback ao longo do caminho ou incentivo a participação; Leaderboards (Status): que servem como comparação entre seus pares; 
Badges (reputação): que "certificam" aos outros seu desempenho ou sua especialização, como acontece nos fóruns de informática ou nos rankings de torrents).

Segundo Mendes (2012), no caso do processo de Ensino/Aprendizagem, tradicionalmente, o conteúdo é apresentado aos alunos de uma forma unidirecional seja sob a liderança de um professor ou até mesmo através de um portal de e-Learning, o aluno recebe o conteúdo e o processa individualmente ou em pequenos grupos. $\mathrm{O}$ progresso dos alunos é mediado pela atribuição de notas individuais. Um dos grandes desafios de qualquer educador é motivar o interesse dos alunos e o progresso da turma. Ainda segundo Mendes (2012), a aplicação de Gamification no processo de Ensino/Aprendizagem pode fazer com que os alunos sejam motivados a cumprir determinadas tarefas ou gincanas para atingir os objetivos do curso. Mais ainda, as tarefas podem incentivar e promover maior interação entre os alunos, possibilitando um desenovlvimento harmonioso da turma como um todo, com metas sendo atingidas de maneira coletiva e não somente através de notas individuais. Desta forma, em vez de ser um treinamento unidirecional, pode-se direcionar os alunos a trocarem experiências e conhecimento, tornando o processo mais dinâmico e atrativo. De acordo com Cohen (2011), o aprendizado baseado em Gamification ainda esta em estado experimental. Ainda existem muitas dúvidas se as mecânicas de um game podem ser mais eficazes que apresentações lineares de conteúdo educacional. A única coisa que se pode dizer com certeza é que a quantidade de experiências em busca de uma resposta para esta dúvida tente a aumentar cada vez mais [LEE \& HAMMER 2011].

Dentro deste contexto, à fim de colaborar com as pesquisas na área de aprendizagem baseada em Gamification, foi desenvolvido um ambiente de ensino de Química Orgânica baseado em Gamification. As seções à seguir apresentam a pesquisa realizada com universitários sobre alguns problemas relacionados ao processo de ensino/aprendizagem que motivaram o trabalho, bem como foi o processo de desenvolvimento do ambiente e os resultados obtidos.

\section{Percepção de Univeristários Sobre o Ensino de Química Orgânica e as Novas Tecnologias}

Buscando entender a visão dos alunos das disciplinas relacionadas da Química Orgânica quanto ao conteúdo ministrado e as ferramentas de apoio existentes, foi feito um levantamento entre os alunos do Centro de Ciências da Saúde da UNIVALI - CCS, matriculados no primeiro semestre de 2013. Este levantamento foi autorizado pelo Comitê de Ética da UNIVALI, sob o parecer número 2012/34 da Plataforma Brasil. Este levantamento auxiliou no estabelecimento da plataforma a ser utilizada neste trabalho, bem como nos elementos de interface a serem contemplados. A seguir serão apresentados os resultados do levantamento.

Participaram do levantamento 86 alunos dos cursos de Biomedicina e Farmácia do 20 ao $4^{\circ}$ período, com idade média de 21 anos, sendo a maioria do sexo feminino, distribuídos nas disciplinas de Farmacologia, Química Orgânica e Bioquímica, conforme mostram os gráficos das figuras a seguir. 


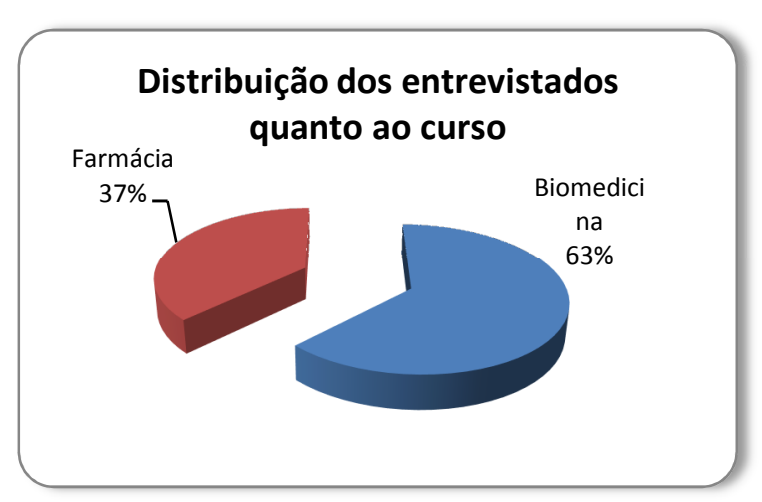

Figura 1. Visão Geral do sistema

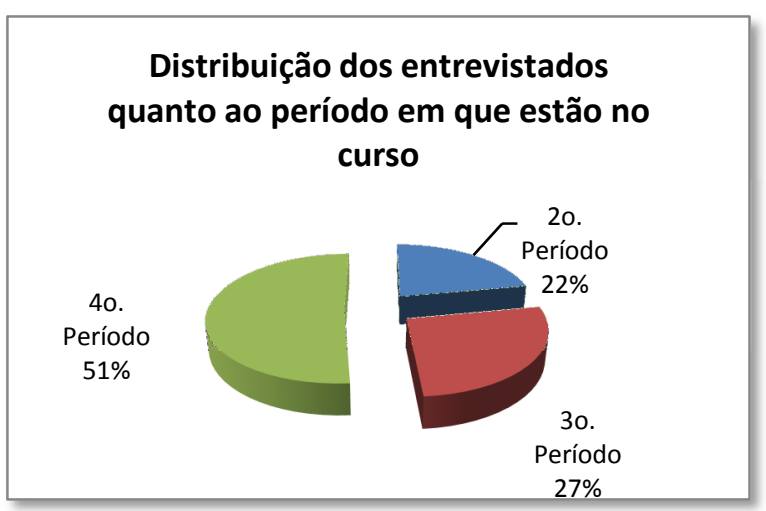

Figura 3. Visão Geral do sistema

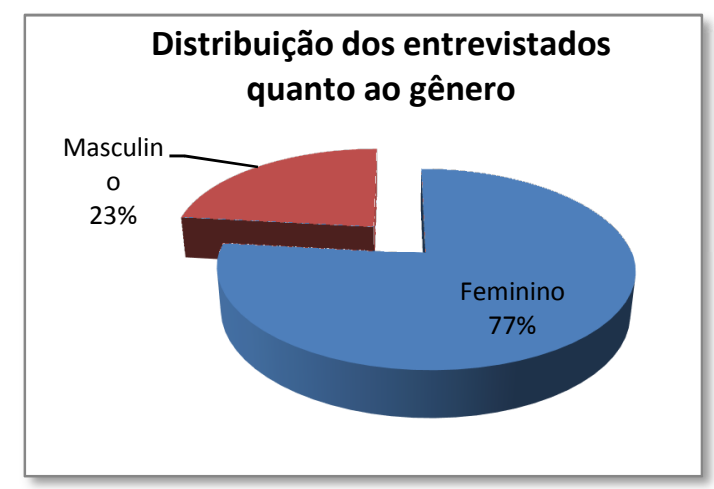

Figura 2. Visão Geral do sistema

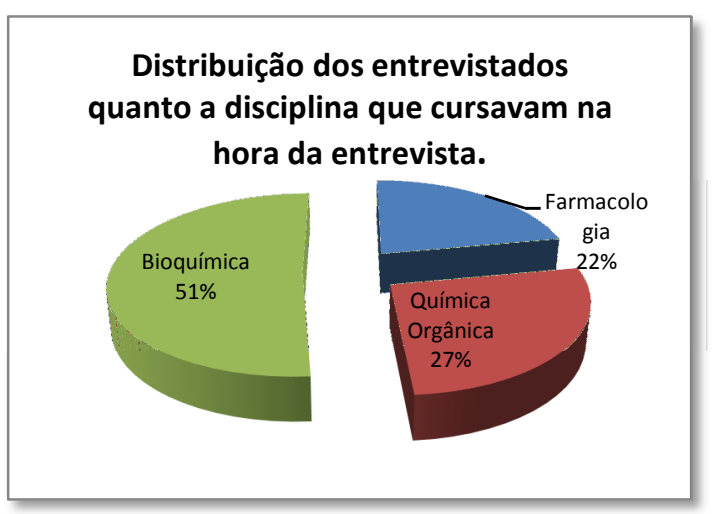

Figura 4. Visão Geral do sistema

Considerando o fator que interfere no aprendizado do acadêmico, os resultados indicam que a linguagem complicada e a falta de ambientes computacionais que lhes auxiliem são fatores importantes, conforme mostra a Tabela 1.

Tabela 1. Fatores que interferem no processo de aprendizagem

\begin{tabular}{|l|l|l|}
\hline \multicolumn{1}{|c|}{ Opção } & \multicolumn{1}{|c|}{ Freq. } & \multicolumn{1}{|c|}{$\%$} \\
\hline Linguagem complicada & 13 & 15,12 \\
\hline Conceitos difíceis de serem visualizados no mundo real & 13 & 15,12 \\
\hline Conceitos muito abstratos, que você não consegue imaginar. & 11 & 12,73 \\
\hline $\begin{array}{l}\text { Falta de alternativas de auxilio aprendizagem, como por exemplo, ambientes } \\
\text { computacionais. }\end{array}$ & 9 & 10,48 \\
\hline Falta de exemplos práticos & 9 & 10,48 \\
\hline Linguagem complicada associada a falta de exemplos práticos & 4 & 4,65 \\
\hline $\begin{array}{l}\text { Linguagem complicada associada a falta de alternativas de auxilio aprendizagem } \\
\text { como por exemplo, ambientes computacionais }\end{array}$ & 4 & 4,65 \\
\hline $\begin{array}{l}\text { Conceitos muito abstratos, que você não consegue imaginar, associados a falta de } \\
\text { alternativas de auxilio aprendizagem como por exemplo, ambientes computacionais }\end{array}$ & 4 & 4,65 \\
\hline $\begin{array}{l}\text { Linguagem complicada, junto com conceitos muito abstratos, que você não } \\
\text { consegue imaginar e conceitos difíceis de serem visualizados no mundo real. }\end{array}$ & 4 & 4,65 \\
\hline $\begin{array}{l}\text { Conceitos muito abstratos, que você não consegue imaginar e conceitos difíceis de } \\
\text { serem visualizados no mundo real. }\end{array}$ & 3 & 3,51 \\
\hline Não responderam & 12 & 13,96 \\
\hline
\end{tabular}

Considerando o que foi apresentado na Tabela 1, percebe-se que o fato complicador mais considerado pelos acadêmicos é a dificuldade de visualização dos conceitos, e o elevando grau de abstração dos conteúdos. Quanto ao material de apoio, $75,58 \%$ (65 alunos), indicaram que utilizam, e 24,42\% (21 alunos) informaram que não 
utilizam materia de apoio. Quanto a natureza do material de apoio, a Tabela 2 apresenta o resultado, valendo lembrar que esta questão era dissertativa, ou seja, cada aluno colocou sua opinião e as mesmas foram agrupadas.

Tabela 2. Tipo de material de apoio utilizado

\begin{tabular}{|l|c|c|}
\hline \multicolumn{1}{|c|}{ Opção } & Frequência & \% \\
\hline Pesquisa na Internet & 31 & 47,69 \\
\hline Vídeos disponíveis na internet & 16 & 24,60 \\
\hline Slides disponíveis na internet & 8 & 12,31 \\
\hline Bulas & 3 & 4,63 \\
\hline Material utilizado no terceirão & 2 & 3,08 \\
\hline Material fornecido pelo professor & 2 & 3,08 \\
\hline Resumos & 1 & 1,54 \\
\hline Livros & 1 & 1,54 \\
\hline Artigos da internet & 1 & 1,54 \\
\hline
\end{tabular}

Percebe-se que a maioria dos acadêmicos utiliza a Internet para apoio, sendo os vídeos e slides disponíveis na Web um dos materiais preferidos dos mesmos. Quanto a sugestões para melhorar o processo de aprendizagem, 63,96\% (55 alunos) disseram não terem sugestões e 36.04\% (31 alunos) apresentaram alguma sugestão. As sugestões apresentadas estão apresentadas a seguir, na Tabela 3.

Tabela 3. Sugestões para melhoria do processo de aprendizagem

\begin{tabular}{|l|c|c|}
\hline \multicolumn{1}{|c|}{ Opção } & Frequência & \% \\
\hline Aulas mais interativas & 8 & 25,80 \\
\hline Uso de softwares & 6 & 3,23 \\
\hline Uso de ferramentas de visualização 3D & 5 & 16,30 \\
\hline Uso de vídeos e imagens & 4 & 13,00 \\
\hline Uso de animações & 4 & 13,00 \\
\hline Uso de jogos educacionais & 4 & 13,00 \\
\hline Estudo em grupo & 1 & 3,23 \\
\hline
\end{tabular}

Quanto as sugestões, os alunos que opinaram, derão como sugestão o uso de aulas interativas e softwares. Considerando isto, buscou-se criar um ambiente web que contemplasse o que os alunos estão acostumados a buscar na web, e acrescentar formas mais interessantes para estudar conteúdos abstratos.

\section{A Ferramenta Desenvolvida}

A ferramenta foi concebida partindo do seguinte princípio: a busca por conteúdos e o estímulo ao aprendizado: considerando a busca por conteúdos, partiu-se do princípio que os alunos buscam material de apoio na web, dando preferência a vídeos, slides, artigos; e considerando o estímulo a aprendizagem, considerou-se as opções de vídeo, imagens e jogos.

À partir disto, buscou-se estabelecer a estrutura do ambiente, contemplando os conceitos de gamification. Os professores não precisam cadastrar turmas no ambiente, mas sim devem cadastrar materiais que auxiliem alunos sobre um dado conteúdo. $\mathrm{O}$ objetivo não é criar um ambiente virtual de aprendizagem, mas sim um ambiente onde os alunos consigam ter acesso a conteúdos de apoio ao aprendizado e sejam estimulados a cumprir as tarefas (jogar por exemplo) para, com isto fixarem conteúdos. A Figura 5 apresenta a visão geral do ambiente. 


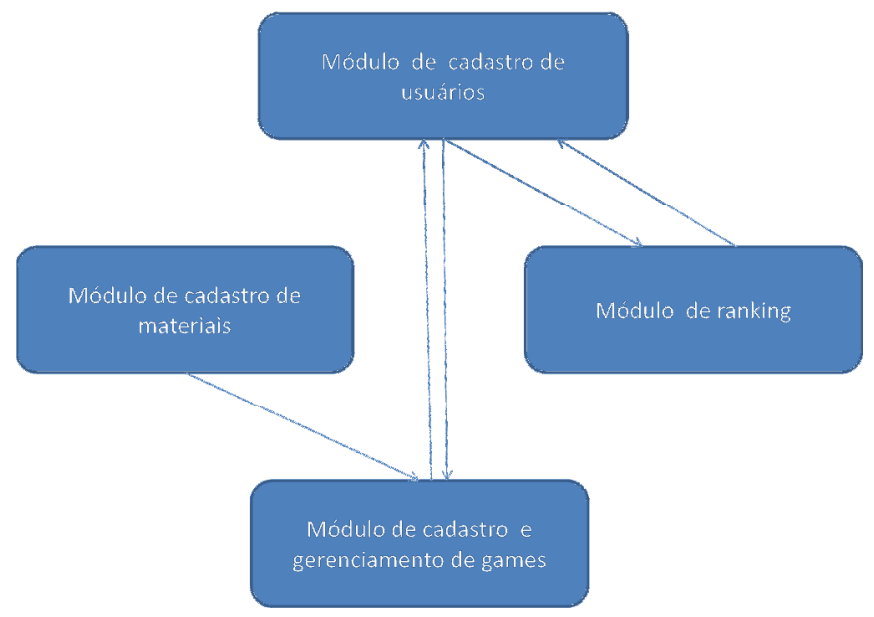

Figura 5. Visão geral do sistema

O ambiente é composto por quadro módulos: Módulo de cadastro de usuários, é responsável por gerenciar os usários que utilizam o ambiente: professores e alunos. Módulo de ranking é reponsável por gerenciar o ranking a partir das recompensas ofertadas pelas atividades disponíveis no ambiente. O módulo de cadastro de materias é responsável pelo gerenciamento dos materiais disponibilizados pelos professores cadastrados no ambiente. Módulo de cadastro e gerenciamento de games é o módulo onde games relacionados ao conteúdo de química orgânica podem ser cadastrados. Cada game ao ser cadastrado deve apresentar um resumo do roteiro do jogo e quais conceitos de química ele abrange.

A Figura 6 apresenta uma das telas do ambiente. Percebe-se que no menu lateral há o ranking dos usuários. Este ranking é atualizado em uma janela de tempo de 24 horas. A Figura 7 apresenta a tela referente aos artigos disponibilizados no ambiente, para que os alunos possam esclarecer dúvidas sobre um dado conteúdo.

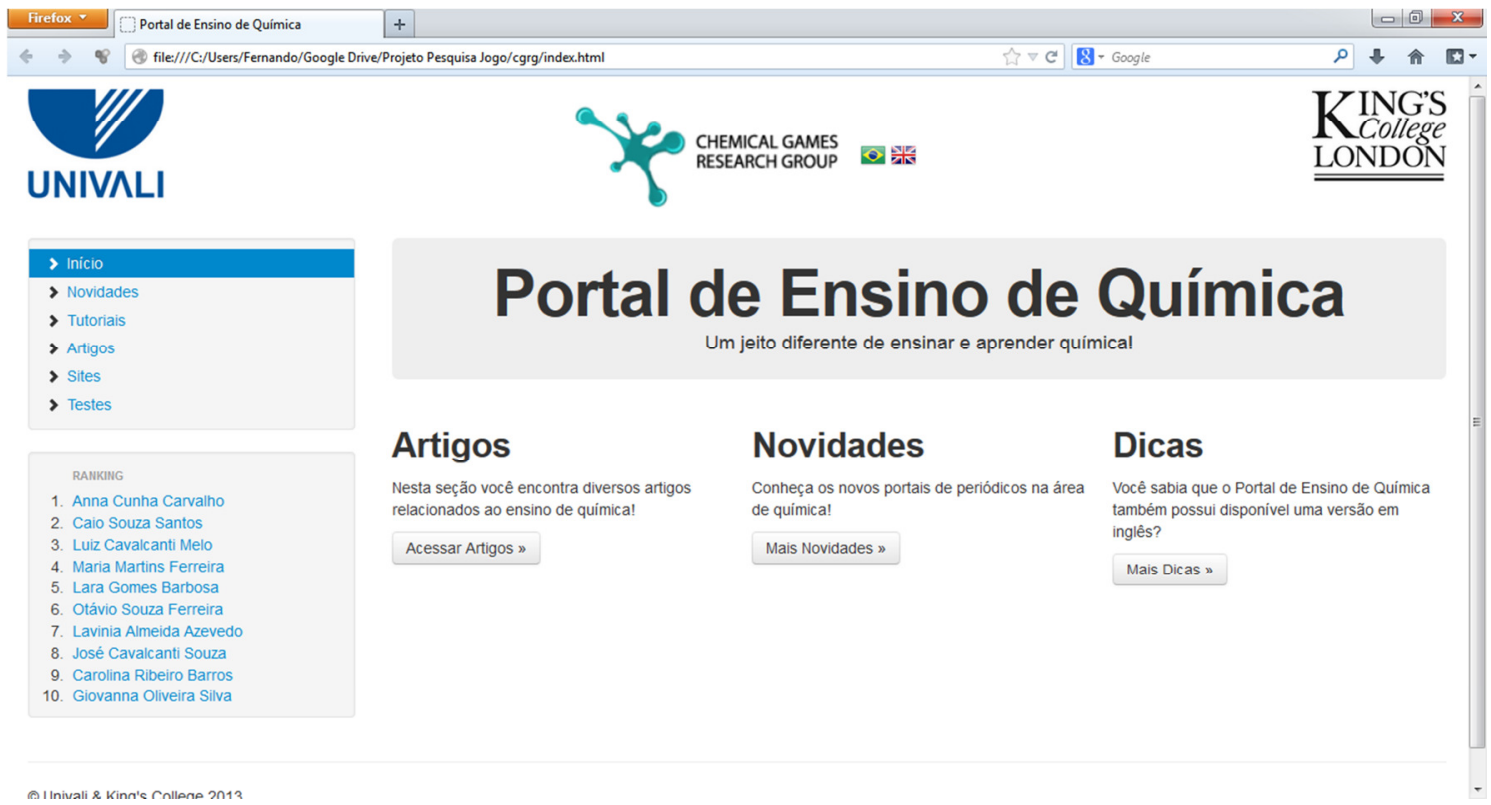

Figura 6. Interface do ambiente. 


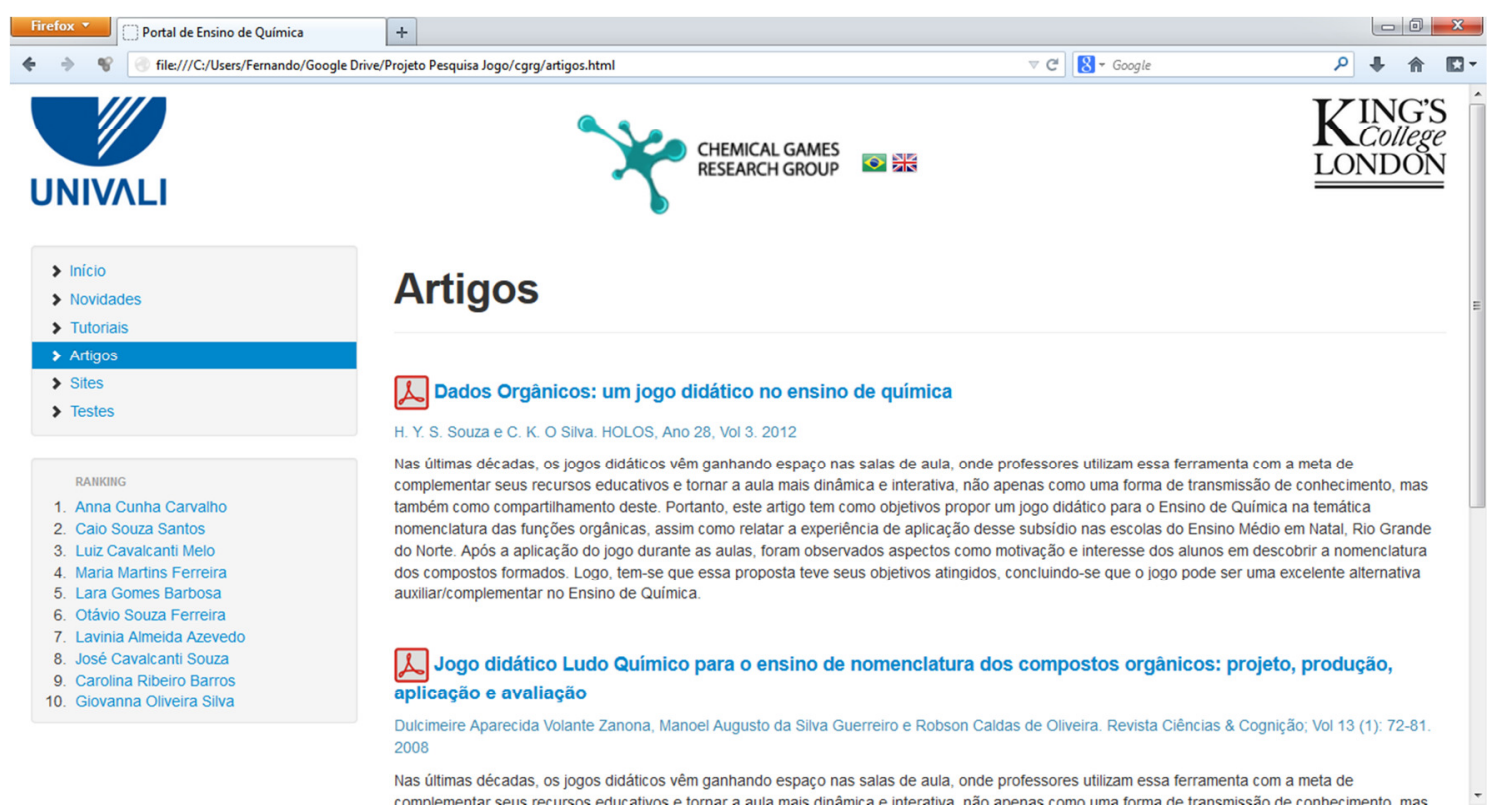

Figura 7 Tela referente a seção de artigos de apoio.

O game disponiblizado no ambiente para avaliar o comportamento dos alunos foi desenvolvido só para este fim. O tema do game são as reações básicas da química orgânica como adição e substituição e tem como foco alunos calouros das universidades. $\mathrm{O}$ enredo que permeia o processo de ensino/aprendizagem baseia-se em um professor de química e seu aprendiz, que deve cumprir as tarefas que o professor lhe passa (todas relacionadas a como ocorre o processo de adição nos compostos orgânicos).

Caso o aprendiz consiga cumprir as tarefas passadas pelo professor ele poderá ter férias mais longas. As tarefas apresentam relações com o dia a dia da pessoal, como por exemplo, o professor precisa ir até o centro da cidade para uma reunião mas seu carro movido a álcool está na reserva, então a tarefa do aprendiz é produzir o combustível necessário. Sendo assim, ele precisa saber qual é o combustível, de que ele é composto e como é possível produzí-lo. Só que para esta tarefa ele tem um tempo associado. Caso estoure o tempo, ele terá mais um dia de trabalho a cumprir, ou seja, menos um dia em suas férias.

O enredo do game é apresentado no ambiente, e o acadêmico ao clicar em jogar, tem a opção de jogar na web ou baixar o game para seu celular e jogar em qualque local a qualquer momento. A Figura 8 apresenta a tela referente as informações do game. 


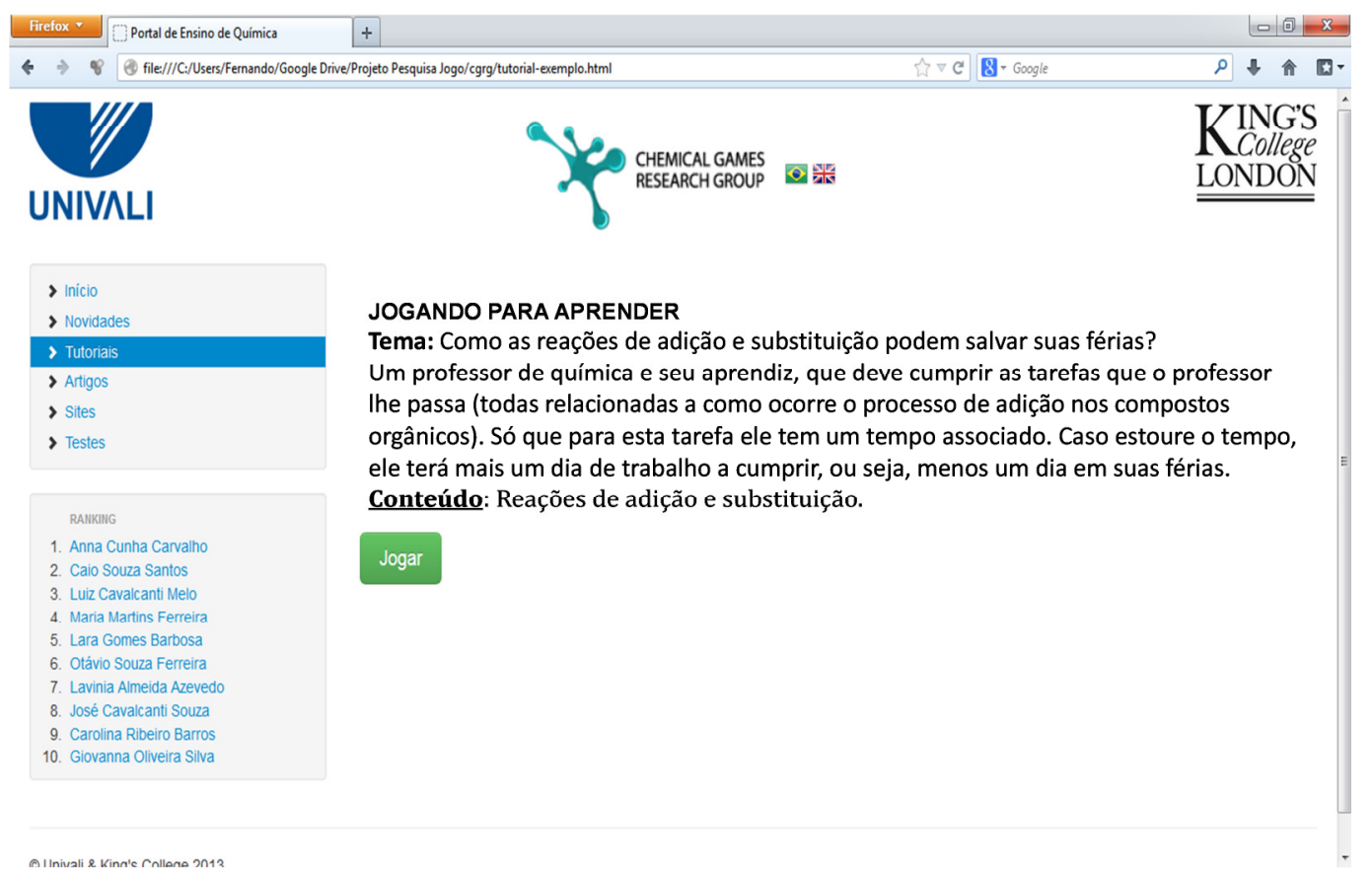

Figura 8. Tela do game cadastrado.

Quando o usuário optar por jogar, abrirá uma outra tela onde ele poderá optar por jogar no próprio ambiente web ou poderá baixar o aplicativo do game para um dispositivo móvel. A Figura 9 apresenta as etapas de uma das tarefas do game executadas em um celular. Após a passagem de cada nível, a pontuação do aluno é passada para o sistema web a fim de atualizar o ranking do usuário.

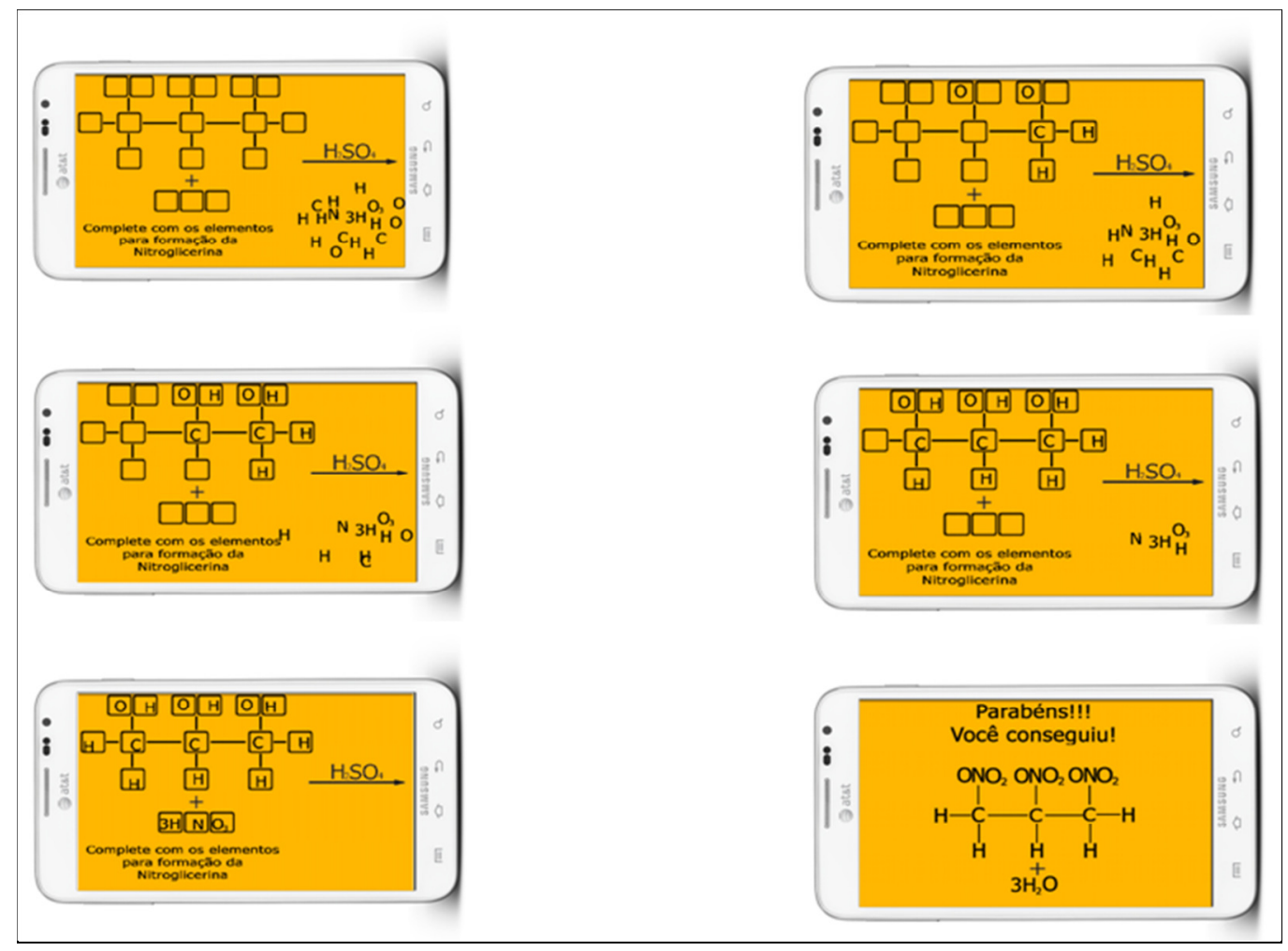

Figura 9 Exemplo de um dos níveis do game para o acadêmico jogar no dispositivo móvel. 


\section{Conclusões}

O ambiente desenvolvido foi testado por professores de disciplinas de química orgânica, e foi aprovado para aplicação em sala de aula, porém, devido a atrasos de implementação não foi possível aplicar nas turmas de 2013/1. Os testes foram feitos então, de maneira informal, em um grupo de 15 alunos que cursaram a disciplina de química orgânica em 2013/1.

A primeira impressão foi de interesse. Os alunos acharam muito interessante o ambiente, pois o mesmo concentra alguns tipos de materiais que eles costumam procurar sempre para complementar os estudos, e o que mais chamou a atenção dos mesmos foi o ranking que o ambiente disponibiliza sobre quem até o momento conseguiu ter mais pontos no game disponibilizado.

O que se percebeu com este grupo foi que a competição informal entre eles e o fato do ranking estar disponível para todos logo na tela principal do ambiente fez com que eles se concentrassem mais na execução das tarefas do game. Todos os acadêmicos que participaram dos testes gostariam de ter mais games disponíveis e queriam também que o ranking pudesse ser associado ao Facebook para que eles pudessem mostrar aos colegas que estão evoluindo (uma espécie de competição onde o status de primeiro do ranking é extremamente importante no convívio social).

Quanto aos aspectos técnicos relacionados ao desenvolvimento da ferramenta, duas questões foram cruciais. A primeira se refe ao desenvolvimento do game. Para que o ambiente seja realmente aplicado no ensino, é necessário que mais games sobre os demais temas que permeiam a química orgânica sejam disponibilizados. Porém, desenvolver um game requer uma equipe multidisciplinar, e o game disponibilizado, apesar de ter sido interessante para um primeiro momento, pode ser considerado como muito simples em termos artísticos e de roteiro. Então, é necessário para uma continuidade de desenvolvimento do ambiente, uma equipe de profissionais de áreas pertinentes ao desenvolvimento de games. Outro fator extremamente importante referese a conexão do ambiente com os dispositivos móveis, que precisa estar mais estável e também é necessário que se tenha um módulo de análise de acessos (mobile analytics e web analytics) para verificar o que realmente os alunos tem acessado e se este acesso pode ser considerado para um futuro estudo sobre melhoria do processo de ensino/aprendizagem.

O ambiente continua sendo implementado no sentido de melhorar as funcionalidades disponíveis e no segundo semestre de 2013 deve ser aplicado em turmas que cursam química orgânica.

\section{Referências}

Aldrich, C. (2009) Learning Online with Games, Simulations, and Virtual Worlds: strategies for online instruction. [S.1.]: John Wiley and Sons.

Antonoglou, L.D.; Charistos, N.D.; Sigalas, M.P. (2011) Design, development and implementation of a technology enhanced hybrid course on molecular symmetry: Students' outcomes and attitude. In: Chemical Education Research and Practice, 2011, vol. 12, 454 - 468.

Azevedo, A.M.P. (2005) Nova tecnologia aplicada ao ensino de bioquímica: construção e validação de um software do tipo jogo. Tese (Doutorado) Programa de 
Pós Graduação em Informática na Educação. Centro Interdisciplinar de Novas Tecnologias na Educação. Universidade Federal do Rio Grande do Sul, Porto Alegre.

Cohen, A.M. (2011) The gamification of Education. Futurist. 45 (5), 16 - 17.

Crisp, M.G.; Kable, S.H., Read, J.R., Buntine, M.A. (2011) The need for innovative methods of teaching and learning chemistry in higher education - reflections from a project of the European Chemistry Thematic Network . In: Chemical Education Research and Practice, 2011, vol. 12, 469.

Eilks, I.; Byers, B. (2010) The need for innovative methods of teaching and learning chemistry in higher education - reflections from a project of the European Chemistry Thematic Network . In: Chemical Education Research and Practice, 2010, vol. 11, 233.

Gregorius,R. M., Santos, R., Dano, J.B., Gutierrez, J.J. (2010) Can animations effectively substitute for traditional teaching methods? Part I: preparation and testing of materials. In: Chemical Education Research and Practice, 2010, vol. 11, 253 261.

Jenkins, H. et al. (2006) Confronting the challenges of participatory culture: media education for the 21th century. Mac Arthur. Acessado em 09 de maio de 2012. Disponível

em $<$ http//www.newmedialiteracies.org/files/workingNMLWhitePaper.pdf $>$.

Lee, J. J., Hammer, J. (2011) Gamification in Education: What, How, Why Bother? Academic Exchange Quarterly, 15(2). Acessado em 02 de junho de 2012. Disponível em: http://www.gamifyingeducation.org/files/Lee-Hammer-AEQ-2011.pdf

Mattar. J. (2010) Games em educação: como os nativos digitais aprendem. São Paulo: Pearson Prentice Hall.

Mendes. F. (2012) Entendendo Gamificiation. Acessado em 02 de junho de 2012. Disponível em http://fgfmendes.blogspot.com.br/2012/03/entendendogamification.html.

Prensky, M. (2007) Digital game-based learning: practical ideas for the application of digital game-based learning. St. Paul: Paragon House, 2007, p. 82 - 8.

Sontag, M. (2009) A learning theory for 21th century students. Innovate, vol. 5, issue 4, 2009. Acessado em 09 de junho de 2012. Disponível em < http//www.innovateonline.info/index.php?view $=$ article\&id=524>.

Strickland, A.M.; Kraft, A; Bhattacharyya, G. (2010) What happens when representations fail to represent? Graduate students" mental models of organic chemistry diagrams. In: Chemical Education Research and Practice, 2010, vol. 11, 293. 